\title{
Análise dos trabalhos do GT Formação de Professores: o que revelam as pesquisas do período 1992-1998
}

\author{
Iria Brzezinski
}

Universidade Católica de Goiás, Centro de Educação

\author{
Elsa Garrido
}

Universidade de São Paulo, Faculdade de Educação

\section{O objeto, o universo e o objetivo da pesquisa}

Este estudo é parte de uma pesquisa mais ampla denominada Estado do Conhecimento sobre Formação de Professores, apoiada pelo Comitê dos Produtores de Informação (COMPED), do Instituto Nacional de Pesquisas e Estudos Educacionais (INEP). Devido à diversidade das fontes, a pesquisa foi dividida em três subtemas: o primeiro dedicou-se à análise dos trabalhos apresentados no Grupo de Trabalho Formação de Professores; o segundo examinou a produção das teses e dissertações divulgadas no CD-Rom da ANPEd; e o terceiro selecionou os artigos publicados em periódicos de circulação nacional. ${ }^{1}$

${ }^{1} \mathrm{O}$ levantamento da produção sobre Formação de Professores a partir das teses e dissertações ficou sob a responsabilidade de Marli E.D. André e Joana Paolim Romanowski. A análise dos periódicos brasileiros foi feita por Janete Magalhães Carvalho e Regina Helena Silva Simões. Os primeiros resultados foram apresentados na $22^{\text {a }}$ Reunião Anual da ANPEd, realizada em Caxambu, de 26 a 30 de setembro de 1999. As autoras agradecem a colaboração
O presente estudo refere-se aos trabalhos apresentados no GT Formação de Professores, durante as reuniões anuais da ANPEd, no período 1992-1998. Os setenta trabalhos analisados constituem uma amostra da produção do GT. Não estão incluídos os pôsteres e as comunicações. Apesar de estes textos terem passado por um processo seletivo e terem sido apresentados nas reuniões anuais, não foram arquivados ou publicados e não puderam ser recuperados. Além disso, foi necessário limitar o alcance desta pesquisa ao período 1992-1998, pois não foi possível localizar grande parte da produção apresentada desde 1983, ano da criação do GT licenciaturas, nome original do GT Formação de Professores.

O conjunto dos trabalhos foi organizado segundo cinco descritores: formação inicial de professores, formação continuada, práticas pedagógicas, profissionalização docente e revisão da literatura. Objetivamos

de Betânea Leite Ramalho, Eduardo Adolfo Terrazzan, Helena Costa Lopes de Freitas e Marcos Villela Pereira, na fase da pesquisa da qual resultou este trabalho. 
identificar os aspectos teórico-metodológicos que embasaram as pesquisas, os resultados alcançados, os focos de análise e as tendências que as produções examinadas parecem sugerir.

Do universo de 70 trabalhos, 28 tratam da formação inicial $(40 \%)$; sobre formação continuada existem 17 trabalhos (24\%); há 11 pesquisas sobre questões relativas à profissionalização docente (16\%) e 10 abordam práticas pedagógicas (14\%); a revisão da literatura foi objeto de quatro estudos $(6 \%)$.

\section{Formação inicial}

Nos dias atuais, a concepção de formação de professores adotada pelos pesquisadores do GT e predominante entre outros investigadores, nacionais e estrangeiros, identifica-se, cada vez mais, com o processo de desenvolvimento contínuo do professor, acentuando-se a unidade desse processo na diversidade de suas fases: formação pré-serviço ou inicial e formação em serviço ou continuada. Desse modo, os investigadores do GT e os gestores das políticas educacionais assumem que, por princípio, formação inicial e formação continuada não são mais do que dois momentos de um mesmo processo. No presente estudo, todavia, desdobram-se a formação inicial e a continuada em dois descritores distintos, porque traduzem melhor a configuração inicial do GT, que, por sua vez, influenciava a temática dos trabalhos apresentados nas reuniões anuais da ANPEd. Conseqüentemente, o subescritor licenciaturas reúne o maior número de trabalhos sobre modalidade normal ${ }^{2}$ e pedagogia.

Do conjunto de 28 trabalhos que trataram da formação inicial, quatro focalizaram os cursos da modalidade normal, oito consideraram a formação dos profissionais da educação em cursos de pedagogia e 16 analisaram a formação de professores nas licenciaturas. A preocupação maior encontrada nas pesquisas

${ }^{2}$ Expressão que desde 1996, após a publicação da lei n. 9.394 (LDB), é usada para denominar a antiga habilitação magistério (nível médio). foi com a formação docente em curso superior. Verificamos um grande esforço dos investigadores para aprofundar o conhecimento dos problemas existentes nos cursos de pedagogia e na licenciatura e propor alternativas para superá-los, visando à melhoria da formação dos licenciandos.

\section{Modalidade normal}

Das quatro pesquisas relativas ao tema, duas examinaram a importância dos fundamentos sociais, históricos e filosóficos na formação e nas práticas das professoras das séries iniciais. Uma delas mostrou a fragilidade dos conhecimentos sociológicos e a pouca importância que as professoras das séries iniciais lhes atribuíam em suas práticas docentes (Simões, 1993). A outra assinalou contradições entre disciplinas teóricas e disciplinas metodológicas: enquanto as disciplinas teóricas ressaltavam o papel da escola como agente de transformação social, as disciplinas metodológicas desenvolviam propostas didáticas conservadoras ou escolanovistas (Souza, 1994).

Dois trabalhos focalizaram aspectos relacionados ao ensino e à aprendizagem nas séries iniciais. Ambos basearam-se em entrevistas e observação de aulas e apontaram deficiências da formação e suas consequiências nas práticas das professoras.

Levantamento empreendido por Gonçales (1995), realizado com uma amostra de 500 sujeitos, registrou atitudes positivas das crianças em relação à matemática e melhor aproveitamento nessa disciplina quando as professoras gostavam da matéria. Verificou também que o pior aproveitamento das crianças em matemática estava associado à falta de entusiasmo da professora em relação à disciplina. Por sua vez, Martins (1998), mediante pesquisa etnográfica, identificou práticas reprodutivistas do desenho em sala de aula, nas séries iniciais do ensino fundamental e no curso de formação de professores em nível médio.

\section{Pedagogia}

Dos oito trabalhos concernentes à formação do pedagogo, dois analisaram o curso de pedagogia e ofereceram uma visão compreensiva sobre formação do 
profissional da educação, nas perspectivas histórica, social e política (Brzezinski,1997; Paiva, Freitas e Scheibe, 1997) e quatro destacaram a existência de contradições entre a proposta curricular e as práticas de formadores e de licenciandos (Damis, 1996; Veiga, 1996; Freitas, 1993; Lima, 1997). Algumas das pesquisas relatadas implementaram práticas inovadoras, visando à superação das deficiências apontadas (Freitas, 1993; Lima, 1997; Sobreira, 1996 e 1998).

Em seu estudo, Brzezinski (1997) distinguiu duas esferas definidoras de políticas educacionais: a do mundo oficial e a do mundo real. Confrontou a nova LDB, lei n. 9.394/96, com as tendências atuais sobre a formação do profissional da educação e o momento socioeconômico brasileiro, realizando comparação entre o disposto no diploma legal e a histórica construção da política global de formação e profissionalização de docentes, engendrada no movimento nacional de educadores. Em seus resultados aponta as limitações existentes na lei, em relação às propostas do citado movimento nacional

O trabalho de Paiva, Freitas e Scheibe (1997) constitui-se em pesquisa documental sobre a história do movimento de reformulação dos cursos de pedagogia e as contribuições para elaboração de propostas curriculares de cursos de formação de profissionais da educação por parte da Comissão de Especialistas em pedagogia da SESu/MEC e da Comissão de Reformulação dos Cursos de Formação do Educador, transformada posteriormente em Associação pela Formação dos Profissionais da Educação (ANFOPE).

Para melhor compreender a realidade dos cursos de pedagogia, duas pesquisas assumiram como objeto de estudo os cursos de duas faculdades públicas. A partir de entrevistas com alunos e professores, constatou-se, em uma pesquisa, a distância entre a proposta curricular e as práticas de ensino (Damis, 1996) e, em outra, o trabalho não articulado dos professores formadores, reforçado pela estrutura institucional fragmentada em departamentos (Veiga, 1996).

Dois relatos de experiência procuraram revelar, ainda que de forma localizada, as deficiências do curso de pedagogia e propuseram inovações para o está- gio supervisionado: Freitas (1993) focalizou a questão da dicotomia entre teoria e prática e Lima (1997) apontou contradições entre o discurso das futuras professoras e sua atuação nos estágios. A concepção de "trabalho pedagógico" como práxis é o foco central da proposta de Freitas (1993); para ela, o trabalho do professor em sala de aula ou no estágio seria também atividade produtora de conhecimento. Essa nova concepção de "trabalho pedagógico" possibilita introduzir o estágio ao longo do processo formativo, formular propostas curriculares interdisciplinares e articular ensino, extensão e pesquisa.

Na proposta apresentada por Lima (1997), o processo de ressignificação das representações e das práticas e a relação entre o pensar e o fazer se deu por meio do uso de metáforas e da atividade reflexiva sobre as contradições entre o discurso e a prática das futuras professoras. Na reflexão a partir dos resultados, a autora sugere que as disciplinas de formação básica incluam em seus programas a reflexão sobre os saberes da experiência, entendendo-se reflexão em dois sentidos: reflexão sobre a prática e reflexão sobre a história de vida.

Finalmente, dois trabalhos sinalizam outra dimensão a ser considerada nos cursos de formação: as representações, de raízes inconscientes, relacionadas à experiência familiar precisam ser trabalhadas, pois influem nas relações professor-aluno (Sobreira, 1996, 1998).

\section{Licenciaturas: configuração inicial do GT}

Dezesseis trabalhos estudaram os cursos de licenciatura. Pesquisa documental feita por Brzezinski (1993), ao longo do período 1980-1992, mostrou a inadequação da formação nos cursos de licenciatura, particularmente no que se refere à dicotomia entre formação pedagógica e formação específica, à fragilidade da formação pedagógica e à descaracterização das faculdades de educação, constituindo mais em (de)formação do que em preparo qualificado para atuar no magistério.

As críticas aos cursos de licenciatura deram origem a debates sobre formação de professores, em âmbito nacional. Em conseqüência, foram criados "fóruns 
de licenciatura" em vários campi. O da Universidade Federal de Goiás foi objeto da investigação de Foerste (1997), mediante estudo de caso, pondo em evidência a falta de projeto para a formação do professor e as tensões entre os professores formadores das disciplinas específicas e aqueles responsáveis pela formação pedagógica. Por sua vez, levantamento empreendido por Basso (1992), sobre o alunado de licenciatura, mostrou que os cursos começavam a ser freqüentados pelas camadas populares, impondo adaptações curriculares para responder a essa nova realidade.

Surgiram também relatos de propostas curriculares inovadoras. Algumas procuraram enfrentar a fragmentação curricular, por meio de eixos articuladores ou de atividades interdisciplinares. Outras desenvolveram experiências envolvendo licenciandos e professores da escola básica em projetos que relacionam teoria e prática ou ensino, pesquisa e extensão.

A análise de um programa de formação de professores procedida por Brzezinski (1992) comprovou a possível articulação entre nove licenciaturas. O projeto, ancorado em princípios de interdisciplinaridade, qualidade e verticalidade do saber, conseguiu estabelecer relações entre as disciplinas das áreas específicas e pedagógicas. Os resultados iniciais revelaram a possibilidade de articulação entre a graduação e a pósgraduação lato sensu e menor índice de evasão dos licenciandos nesses cursos, bem como evidenciaram ações de valorização da profissão docente, tanto no contexto da universidade como nas políticas desenvolvidas pelas secretarias de educação estadual e municipal. A pesquisa revelou, ainda, a importância da interdisciplinaridade nos programas de formação de profissionais da educação, assim como confirmou a concepção de formação assumida pelos pesquisadores do GT, mencionada anteriormente, na qual a formação é identificada, cada vez mais, como processo contínuo de desenvolvimento do professor.

O trabalho de Taffarel (1994) também apresenta proposta de natureza interdisciplinar, realizada em um curso de licenciatura de educação física. A investigação envolveu observação e gravação de aulas em vídeo, além de entrevistas com alunos e professores, objetivando entender as dificuldades, as contradições, enfim a dinâmica da proposta inovadora que estava sendo implementada. Em trabalho anterior, a autora já havia apresentado estudo sobre a história e as tendências atuais da formação do professor de educação física (Taffarel, 1992).

Outra pesquisa, realizada por Ludke e Goulart (1994), compreendeu dois estudos de caso sobre experiências em curso de licenciatura, baseadas também em eixos interdisciplinares. Disciplinas integradoras foram criadas com a finalidade de estabelecer pontes entre disciplinas teóricas e práticas. Em uma licenciatura de física esse papel articulador foi exercido por uma nova disciplina denominada "instrumentação para o ensino" , cuja experiência foi apresentada por Viana (1992).

Atividades articuladoras entre teoria e prática passaram a integrar vários programas de estágio supervisionado e de metodologia e prática de ensino, adquirindo diferentes nuances conceituais. Na experiência de Angotti (1994), os futuros professores desenvolvem projetos em que procuram relacionar os conceitos da física ao cotidiano dos alunos, ao mesmo tempo em que o futuro professor é introduzido na vivência dos processos investigativos. Na proposta de Carvalho (1992), também voltada para a formação do professor de física, os projetos desenvolvidos pelos estagiários em sala de aula assumiram fundamentação teórica baseada no construtivismo piagetiano. Neste caso, o licenciando, além de vivenciar os desafios da prática e de tomar consciência da incongruência entre o discurso progressista e a prática conservadora, transforma seu processo de aprendizagem sobre o ato de ensinar como atividade investigativa. Em decorrência, procura entender os pressupostos do ensino construtivista, tomando-o como fundamento de seu projeto, e documenta a experiência vivida para poder analisar as dificuldades encontradas, as razões da contradição entre a intencionalidade e a ação e as transformações que essa nova postura traz no cotidiano da sala de aula. Nessas experiências a construção dos saberes docentes não se reduz ao conhecimento de teorias inovadoras; inclui a vivência e a reflexão sobre a prática. 
A abordagem construtivista, que tem fundamentado grande parte das pesquisas sobre ensino de ciências e matemática, impôs a necessidade de serem esclarecidas a especificidade e as relações entre diferentes sentidos do termo "conhecimento" . Quais as diferenças entre o conhecimento cotidiano trazido pelo aluno, a ciência ensinada nas escolas e a ciência produzida pela comunidade científica? Até que ponto o professor é um pesquisador? Essas questões epistemológicas e suas implicações na prática pedagógica foram objeto de um estudo conceitual realizado por Colinvaux (1993).

Os trabalhos indicam que propor cursos de licenciatura a partir de pressupostos construtivistas significa também rever o conceito de "educação científica" e repensar o currículo de formação do professor. Ensinar passa a exigir do professor nova postura sobre a construção histórica do conhecimento científico; não basta conhecer os conteúdos específicos; é preciso compreender como esses conteúdos foram concebidos e transformados pela comunidade científica ao longo da história. Ensinar exige também entendimento sobre como o estudante constrói o conhecimento e como o professor pode favorecer esse processo. Mazzotti (1993) argumenta que mais importante do que dotar o professor de conteúdos científicos é dotá-lo de postura científica, fundada na história da ciência e na epistemologia genética. Castanho et al. (1992) abordaram o tema a partir do enfoque sociointeracionista.

Diante desse novo quadro teórico que entende o conhecimento como processo de contínua (re)construção, cabe investigar sobre as representações prévias dos licenciandos. Rosso e Etges (1996) constataram, entre os licenciandos das áreas de ciências e matemática, concepções de educação descontextualizadas, imprecisas, ambíguas, que supunham visão essencialista do homem. Outro estudo procurou detectar as atitudes preconceituosas de licenciandos de ciências e de matemática em relação ao ensino, considerado por eles como atividade menos nobre do que a pesquisa (Pereira, 1997). Os autores sugerem a importância do formador conhecer e elaborar cientificamente as opiniões advindas do senso comum que os futuros professores têm sobre conhecimento, ensino, aprendizagem, pois elas influem em suas atitudes e aparecem em suas práticas docentes por ocasião dos estágios.

O conjunto desses trabalhos oferece contribuições para subsidiar formulações para os cursos de formação de professores. Estas referiram-se sobretudo às propostas curriculares interdisciplinares e às transformações nas disciplinas metodologias de ensino e práticas de ensino, responsáveis pelo estágio supervisionado, e foram marcadas pela reflexão sobre os saberes da experiência pessoal do licenciando e pelo desenvolvimento de projetos pedagógicos teoricamente sustentados.

Em face do que analisamos nos trabalhos, é possível concluir que eles oferecem perspectivas para uma nova concepção de formação inicial do profissional da educação. As relações entre os referenciais teóricos e a prática neles expressas permitiram constatar que o saber se articula ao saber fazer e ao saber ser. Desse modo, conhecimento, experiência, valores e compromissos integram-se. A esse respeito, partilhamos a idéia de Alarcão (1998a) de que

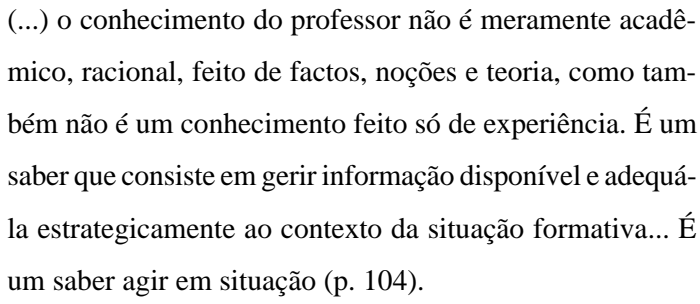

Como contraponto às propostas até aqui analisadas, o ensaio de Melo (1995) focaliza e questiona as mudanças que vêm ocorrendo nos setores produtivos. Para a autora essas mudanças superdimensionam a importância da ciência e da tecnologia, trazendo como conseqüência uma nova lógica de organização curricular das licenciaturas, fazendo ressurgir o enfoque sistêmico.

A análise das investigações feitas até este momento reconfirmou a necessidade de uma política de formação de professores que articule as duas fases do processo de desenvolvimento profissional do docente: a formação inicial e a formação continuada. 


\section{Formação continuada: nova proposta para o G T}

A formação continuada foi objeto de dezessete trabalhos.

Pesquisadores participantes do Projeto de Rede Pública de Ciência, Matemática e Educação Ambiental de Pernambuco desenvolveram um projeto construtivista de formação continuada com professores de matemática do ensino fundamental (Aguiar et al., 1993). A pesquisa mostrou que a mudança mais significativa consistiu na busca de adequação dos conteúdos matemáticos ao cotidiano dos alunos.

Carrer et al. (1995) descrevem a realização de oficinas de leitura a professores da rede municipal $\left(1^{\text {a }}\right.$ a $4^{\text {a }}$ série), ao longo do ano letivo. As teorias da ação comunicativa, de Habermas, e sociointeracionista, de Vigotsky, embasaram o estudo. As pesquisadoras utilizaram a literatura infantil como eixo articulador para o desenvolvimento de projetos de leitura e de escrita e como estímulo à reflexão sobre as práticas pedagógicas das professoras. A experiência favoreceu a interação do grupo e mobilizou os professores para uma atuação autônoma e mais eficaz. As mudanças em sala de aula mostraram maior autonomia das crianças e melhoria na relação entre professor e alunos e entre alunos.

Os dois projetos acima referidos favoreceram parcerias entre as universidades e as secretarias da educação. Os trabalhos revelaram também que as experiências construtivistas e interacionistas confirmam que o saber e o saber fazer docente são construções dos sujeitos e que a mudança das práticas requer a ressignificação das representações. Tais transformações não ocorrem por simples transmissão; não ocorrem tampouco de forma abrupta ou imediata: constituem um processo que dá continuidade à formação inicial.

A partir de 1996, a tônica da formação continuada centrou-se na reflexão dos professores sobre suas práticas e sobre as práticas escolares. Os investigadores buscam entender os problemas do cotidiano escolar como base para a criação de alternativas transfor- madoras, fundamentadas na abordagem do professor reflexivo. Nessa perspectiva, o leque de questões examinadas amplia-se. A formação passa a desenvolverse preferencialmente no âmbito da instituição escolar, na qual o profissional exerce suas atividades, envolvendo todo o corpo docente e, por vezes, membros da equipe e da comunidade escolar. Stenhouse (1986), Schön (1987, 1992), Nóvoa (1992a e b), Garcia (1992), Zeichner (1993), Perrenoud (1993), Gimeno Sacristán (1996) e Alarcão (1998a) têm sido os grandes inspiradores dos trabalhos de formação continuada do professor reflexivo.

Diante dessa nova concepção de formação continuada, vai sendo ultrapassada a idéia de que a formação em serviço seja realizada em treinamentos. As críticas sobre essa modalidade de capacitação são recorrentes e tornam-se cada vez mais qualificadas e contundentes. Rejeitam-se os encontros e cursos intensivos e rápidos, "massificados”, assim como os "pacotes encomendados", produzidos à distância das salas de aula, que não valorizam os saberes construídos pelos professores, não relacionam os aspectos teóricos aos problemas concretos vividos pelos docentes e propõem atividades descontextualizadas do projeto político-pedagógico da escola (Martins, 1994; Andaló, 1995; Levy e Puig, 1998). Martins (1994) denunciou as práticas mecanicistas de "treinar professores" de $1^{\text {a }}$ a $4^{\mathrm{a}}$ série da escola rural; elas se mostraram incapazes de transformar a escola localizada no campo.

Andaló (1995) procurou diferenciar o "aperfeiçoamento docente em serviço" do "treinamento em serviço" recomendado pela Qualidade Total em Educação. Questionou o aperfeiçoamento docente como uma das formas que têm sido apontadas para solucionar o fracasso da escola pública brasileira, bem como as alternativas neotecnicistas que se desenham no campo educacional. Abordou a resistência dos docentes às tentativas de modificação do seu "saber-fazer" . Nas conclusões, discutiu as dificuldades de implementação do "aperfeiçoamento docente em serviço", diante da crescente deterioração da rede pública de ensino.

Levy e Puig (1998) criticaram os cursos padronizados e propuseram um método didático para a forma- 
ção mais individualizada na pós-graduação e uma relação mais dialógica entre professores da universidade e professores de ciências que atuam no ensino fundamental e médio, de modo que eles próprios, partindo de suas concepções e de suas práticas, possam propor mudanças, transformando-se em autores de sua prática.

Em outro trabalho que enfoca o professor reflexivo, Grillo et al. (1998) partiram dos estudos empreendidos na disciplina prática de pesquisa de professores reflexivos do programa de pós-graduação stricto sensu da PUC/RS, mostrando, através de estudos etnográficos, que os professores universitários, em suas práticas diárias, foram reflexivos, em maior ou menor grau, reconstruindo cotidianamente seu saber docente.

Os primeiros relatos de práticas de reflexão coletiva mostraram que a criação de espaços de discussão sistemática contribuiu para mudar as práticas docentes (Prette e Prette, 1997; Silva e Schnetzler, 1998).

Prette e Prette (1997) valem-se das abordagens sociogenética, de Perret-Clermont e Coll, e sociointerativista, de Vygotsky, para promover discussões, entre os professores que se aperfeiçoam, sobre a aplicação, na educação, do conceito de habilidades sociais e sua relação com o papel do professor na sala de aula. Os pesquisadores trabalharam com propostas de desenvolvimento interpessoal e sociopolítico como objetivo de ensino, propostas implícitas nos novos paradigmas culturais e educacionais, e apontaram para a exploração de recursos instrumentais e metodológicos de avaliação e para o desenvolvimento de habilidades interpessoais que podem ser fundamentais à implementação de condições interativas de ensino. A nosso ver, o maior mérito desse trabalho foi aperfeiçoar, pela formação continuada, professores atuantes no ensino médio de escolas públicas do interior paulista, nível de ensino bastante silenciado.

Silva e Schnetzler (1998) trabalharam com professores de ciências do ensino fundamental e médio. A partir da problematização de suas práticas, os professores propuseram alternativas conjuntas e desenvolveram projetos implementados, discutidos e aperfeiçoados, transformando o ensino em pesquisa-ação. A metodologia desta pesquisa permitiu que a ação docente se tor- nasse objeto sistemático da análise dos professores, pois as práticas pedagógicas foram continuamente observadas, pensadas, avaliadas e transformadas.

Seguindo a mesma linha de pesquisa, Carvalho e Simões (1996) procuraram demonstrar como a reflexão sobre o cotidiano escolar relaciona o pensar com o agir. A reflexão, fertilizada pela teoria, faz com que os professores atuem para além do imediatismo e do conformismo, em defesa de uma instituição escolar comprometida com as camadas populares.

Sordi e Camargo (1998) chegaram a conclusões semelhantes. No processo de formação, o professor não só modifica sua prática, mas recupera seu status profissional e político quando revê e fundamenta a sua própria qualificação e, em um contexto coletivo, toma decisões sobre sua prática pedagógica.

Em dois outros projetos, Marin (1998) e Garrido (1998) apresentaram os caminhos percorridos no processo de formação do professor reflexivo na perspectiva da pesquisa-ação. Cada uma das autoras faz parte de um grupo integrado de pesquisa colaborativa universidade-escola e tem como parceiros um Centro de Formação do Magistério (CEFAM) localizado em Araraquara e outro situado na cidade de São Paulo. As autoras relataram a conquista da confiança mútua, a organização do grupo, as tomadas de decisão coletivas, a problematização da escola, os primeiros projetos investigativos, as tensões, os dilemas, as conquistas. Destacaram o papel do pesquisador na conquista da reflexão crítica, na aprendizagem de procedimentos de pesquisa e na introdução da cultura de registro e de análise. As pesquisadoras consideraram ainda questões de ordem metodológica e epistemológica colocadas pela pesquisa-ação. Indagaram, por exemplo, sobre o que diferenciaria uma pesquisa-ação colaborativa de um trabalho de extensão. Discutiram a questão ética, qual seja: até que ponto a publicação dos resultados pode influir na vida dos professores participantes.

Dickel (1998), baseada na teoria do professor reflexivo, realizou estudo teórico sobre o pensamento de Stenhouse (1986), tendo por objeto o professor-pesquisador. Na perspectiva do trabalho do autor estudado, o professor é considerado como profissional que 
produz conhecimentos pedagógicos, a partir da reflexão e criação de alternativas para melhorar o ensino e a aprendizagem, com o desenvolvimento de trabalho de avaliação contínua e desenvolvimento do projeto político-pedagógico da escola.

As pesquisas analisadas mostram que a formação do professor-reflexivo ganha dimensão crítica. Ao serem estimulados a pensar sobre os condicionamentos histórico-institucionais das práticas pedagógicas e sobre a dimensão ético-política da ação educativa, os professores tomam consciência de que "a prática pedagógica é uma atividade que gera cultura, à medida que é praticada, portanto, a prática docente em movimento é produtora de conhecimento, ela é praxis" (Gimeno Sacristán, 1991, p. 83).

O estudo de caso realizado por Polletini (1997) volta-se também para a prática docente. A autora explora, no entanto, o poder de pressão que pode estar subjacente aos processos de mudança das práticas pedagógicas, apresentando as mudanças ocorridas com uma professora de matemática, cerceada em sua autonomia sob a pressão da diretora da escola, adepta da administração centralizada.

Uma única pesquisa dedicou-se à avaliação dos programas de formação continuada. Carrer et al. (1996) selecionaram para estudo doze programas, implementados em cinco regiões do país. Ressaltaram a importância da parceria com a universidade e a necessidade de políticas de formação continuada, para que as mudanças provocadas não se tornem apenas ações isoladas. Melhores resultados foram obtidos quando o conjunto dos professores de uma escola participava do programa. Entretanto, as autoras chamaram a atenção para a falta de ressonância desses projetos no desempenho dos alunos, reforçando a necessidade de avaliar-se o impacto dos programas na melhoria da qualidade de ensino.

Dos 17 trabalhos analisados sobre formação continuada somente dois dedicaram-se às políticas dessa modalidade de formação: Veiga et al. (1993), da Universidade de Brasília, e Feldfeber (1995), da Universidade de Buenos Aires. Ambos, nas devidas proporções, denunciam as conseqüências educacionais pouco comprometidas com o rigor acadêmico e com a formação de profissionais críticos.

A análise documental e as entrevistas realizadas pelas pesquisadoras do grupo de Veiga, com os coordenadores de vinte projetos de formação continuada, conduzidos pela Faculdade de Educação da Universidade de Brasília (UnB), no período 1991-1993, serviram para denunciar um desserviço prestado pela universidade à escola básica pública. A ausência de uma política da UnB para a oferta de atividades de extensão, voltadas para a educação continuada, impedia que os programas se centrassem nas prioridades da educação fundamental. Entretanto, a formação continuada, por eles propiciada, respeitava a carga horária mínima estipulada para a carreira do magistério pela Fundação Educacional do Distrito Federal, oferecendo um certificado útil à ascensão funcional.

Em relação às políticas argentinas, Feldfeber (1995) realizou pesquisa teórica bastante densa, colocando sob suspeita as recomendações e imposições dos organismos internacionais, assim como as políticas implementadas pelo Ministério de Cultura e Educação daquele país. Questionou a validade da política de descentralização dos serviços educativos e a implementação da lei federal, que obriga a avaliação da qualidade das instituições escolares, detendo-se na análise das propostas de formação e capacitação docentes. Segundo a autora, a política de descentralização mediante a qual se transferem responsabilidades para as "províncias" responde, principalmente, a um repasse das obrigações, impulsionado por motivos econômicos no marco das políticas neoconservadoras de ajuste e contenção dos gastos públicos.

Quanto às políticas de formação docente, a pesquisadora destaca quatro aspectos vigentes na Argentina: a) as políticas obedecem à lógica da formação inicial aligeirada, privilegiando a reciclagem e a capacitação em serviço; b) inexistem programas sistemáticos de formação permanente dos docentes em exercício; c) o aperfeiçoamento e a qualificação do magistério são feitos graças à iniciativa individual do professor; d) a criação de uma rede federal de formação contínua limita-se a um sistema que disponibiliza informações 
para os professores. A autora evoca, nas conclusões, a importância da formação de docentes críticos, que possam questionar essas imposições com o objetivo de transformar essa realidade.

Tais políticas, assumidas pela maioria dos países latino-americanos, no bojo do neoliberalismo, definem prioridades para os seus sistemas educacionais, violentando sua soberania, porque submissos aos ditames dos acordos internacionais. A profissionalização do professor é entendida como produtora de resultados eficientes, aferidos basicamente pelo desempenho do alunado nos exames nacionais. Contrapõem-se a essa pseudo-profissionalização os trabalhos apresentados no GT Formação de Professores, pautados pela valorização da identidade e desenvolvimento da profissionalização docente.

\section{Profissionalização docente: tema recorrente nos trabalhos do G T Formação de Professores no período 1994-98}

A produção do conhecimento nos onze trabalhos sobre a identidade e profissionalização docente, sem dúvida, foi influenciada pela temática que orientou as reflexões no GT, durante as reuniões anuais da ANPEd, no período entre 1996-1997, qual seja: "Conhecimento e profissionalização docente" . Esse tema foi escolhido pelo GT Formação de Professores diante da permanente crise de identidade vivida pelo professorado e da necessidade de se desenvolverem pesquisas na tentativa de superá-la.

A crise do professorado tem sido marcada, entre outros, pelos seguintes aspectos:

a) ambigüidade do trabalho docente, que se apresenta em um movimento pendular entre profissionalismo e proletarização (Enguita, 1991);

b) falta de reconhecimento social do professor na sociedade contemporânea, fonte de mal-estar entre os docentes (Villa,1998);

c) perda do controle de suas qualificações (Apple e Teitelbaun, 1991); d) ausência de sentimento de pertença a uma categoria profissional (Nóvoa, 1991; Enguita, 1991; Brault, 1994; Rodrigues, 1997; Alarcão, 1998b; Villa, 1998);

e) polissemia do termo formação do professor (Alin, 1996);

f) "jogo interior de máscaras e espelhos com que os docentes se confrontam consigo próprios, no interior da sala de aula" (Carrolo, 1997, p.23);

g) exigência de domínio de um conjunto de saberes diversificados (Apple e Teitelbaun, 1991).

Esses aspectos, entre outros, foram objeto de estudos apresentados por Nuñez e Ramalho (1997), Chakur (1994), Villa (1997), Birgin (1998), Silva (1994) e Pereira $(1996,1997)$. Os dois primeiros praticamente definem modelos para a construção da identidade e da profissionalização, porém Nuñez e Ramalho (1997) direcionam seu modelo para a formação préserviço e Chakur (1994) apresenta uma hierarquia de níveis a partir de uma experiência com formação continuada.

O trabalho de Nuñez e Ramalho (1997) apresenta um "modelo profissional", cuja reflexão teórica inclui os estudos sobre a construção da profissão docente, realizados no programa de pós-graduação em educação da Universidade do Rio Grande do Norte. Os autores dirigem suas críticas para a inexistência de projetos político-pedagógicos para nortear as ações de formação inicial dos professores. Referenciados na teoria da atividade, definem elementos e ações para a construção da identidade do professor na formação pré-serviço, bem como estabelecem as múltiplas funções, relações e finalidades da aplicação do modelo proposto, que deve ser formulado em termos de objetivos gerais, flexíveis e abertos, expressos como habilidades, competências e atividades básicas que identificam o "núcleo da profissão". O "modelo de formação" deve ser tomado como referência epistemológica e deve respeitar a especificidade dos processos formativos e das instituições formadoras.

Chakur (1994), mediante pesquisa empírica, fundamentada no construtivismo piagetiano, procurou tra- 
zer à comunidade acadêmica uma leitura do processo de construção profissional do professor. A partir dos resultados da investigação, elaborou um modelo expresso em uma hierarquização de níveis que sustentam o processo de construção da identidade e profissionalização docente desenvolvido pelo professor em suas práticas. Essa proposição de níveis levou-nos a incluir esta investigação sob o descritor profissionalização, retirando-o do conjunto sobre formação continuada, ao qual aparentemente o trabalho possa pertencer.

Os trabalhos de Villa (1997) e de Birgin (1998) aproximam-se, notadamente por um aspecto: em suas pesquisas exploratório-descritivas, os autores discorrem sobre as ameaças que pairam sobre a identidade profissional, dadas as mudanças culturais, sociais e econômicas e a reestruturação do mundo produtivo e do trabalho, influenciada pela revolução tecnológica e pela mundialização da economia, presentes na sociedade contemporânea.

De modo particular, a partir da análise das causas do mal-estar docente que atravessa a classe do magistério na Europa, Villa (1997) concluiu que a cultura e a ciência, que o professor sempre representou enquanto intelectual, perdem seu caráter e a identidade profissional e alteram-se pela redefinição das relações entre sexos, idades, e entre pais e filhos. Concluiu ainda que as tarefas exigidas do professor de hoje são cada vez mais numerosas, o que requer a ressignificação de sua identidade e formação para abranger diferentes áreas do conhecimento.

Por seu turno, Birgin (1998) explicitou a existência de um processo de reconstrução da docência, que coloca como foco central as competências exigidas devido às trocas instantâneas dos chamados conhecimentos teletácitos, em face das novas tecnologias de informação e de comunicação. Os resultados deste estudo indicam ainda a reconceituação dos termos qualificação, qualificação tácita, apropriação e expropriação do conhecimento e a necessidade de reinventar a escola.

No conjunto desses trabalhos que tratam da identidade do professor, certa singularidade marca a pes- quisa de Silva (1994), pois é a única que delimita o campo de desenvolvimento da pesquisa nas séries iniciais do ensino fundamental e que delineia a identidade social e profissional do professor "polivalente" . Como fonte de informações, a autora utilizou a produção escrita de uma prova de concurso público para o magistério da cidade de Florianópolis (SC), complementando essas informações com os dados acadêmico-biográficos, extraídos da documentação apresentada pelos candidatos nas provas de títulos. Procedeu à análise das representações dos professores habilitados para atuarem ou que atuavam nas séries iniciais do ensino fundamental, acerca de aspectos e valores da sua identidade. As conclusões mostraram que a pouca autoestima e as difíceis condições de vida e de trabalho dos professores produzem um mecanismo de transferência das causas dos fracassos para aspectos que isentam a atuação profissional, o que vai configurando uma prática pedagógica ausente de autocrítica.

Os dois outros trabalhos analisados, ambos de Pereira $(1996,1997)$, se complementam. No primeiro, utilizando-se do trabalho interdisciplinar como estratégia de produção da subjetividade na formação, o autor defende a idéia de a interdisciplinaridade possibilitar ao sujeito assumir a gestão de si mesmo, de auto-referenciar-se e produzir, a cada vez, o novo, o outro, o diferente. No segundo, Pereira estuda a produção da subjetividade do professor, associada à idéia da indissociabilidade do coletivo e do individual, de modo que cada escolha seja carregada de responsabilidade e de intencionalidade. Se no primeiro trabalho Pereira elegeu a interdisciplinaridade como elemento fundante de sua teorização, no segundo recorre ao método autobiográfico para reconstituir, com a história de vida e com a memória dos professores sujeitos de sua investigação, a "estética da professoralidade" . Fundamentando-se em Deleuze (1987), Guattari (1992) e Foucault (1991, 1993, 1994), para a identificação dos modos e possibilidades de interferir nos fluxos de atualização do "devir professor", o autor rejeitou o modelo de identidade estática e buscou a processualidade que compõe o "devir professor" . Em termos metodológicos, o se- 
gundo trabalho de Pereira inscreve-se no mesmo grupo dos trabalhos de Bueno et al. (1994), Assunção (1995), Moraes (1996), Bueno (1997) e Morgade (1998), dos quais trataremos a seguir.

Em que pese o emprego relativamente novo do método autobiográfico na área educacional, a densidade das investigações de Bueno e colegas da USP, bem como as de Assunção e Moraes revelam a importância do "ouvir a fala" das professoras. As professoras informantes, ao rememorarem o passado confrontado com as experiências do presente, permitiram que as pesquisadoras, ao analisarem essas falas e aplicarem os resultados, se tornassem coadjuvantes das mudanças provocadas nas práticas pedagógicas de professoras de $1^{\text {a a }} 4^{\mathrm{a}}$ série (Assunção, 1995), de alunas do ensino médio da habilitação magistério e do curso de pedagogia (Bueno et al., 1994; Bueno, 1997) e de uma professora de leitura (Moraes, 1996).

Esse método é relevante para a reconstrução das concepções de profissional da educação e das práticas das professoras, e os resultados das pesquisas apontam para:

a) a geração de uma contra-memória profissional, à medida que as professoras vão demolindo as idéias que lhes foram impostas pela memória oficial e pelos próprios livros didáticos (Bueno et al., 1994);

b) a demonstração de que o processo formativo não é linear, nem cumulativo, tampouco resultante exclusivo da formação acadêmica, mas se dá em um movimento no percurso da carreira profissional, comportando rupturas e redefinições resultantes da construção de um pensar e de um agir profissional contextualizado, com momentos de satisfação e de angústias, provocando profundas mudanças na prática das professoras (Moraes, 1996);

c) a comprovação do reforço contínuo dado pela cultura escolar aos determinantes da "escolha" pelo magistério, por "vocação", pelas condições de gênero, pela classe social ou pela influência da mãe (Assunção, 1995).
As questões de gênero e as relações de poder nos escalões hierárquicos do sistema escolar argentino é o objeto da pesquisa de Morgade (1998). Temática pouco explorada nos trabalhos do GT, tem significado para a construção da identidade profissional, que se revela proporcional à importância da rememoração das histórias de vida das mulheres professoras para a construção de uma contramemória profissional. A partir da reconstituição histórica, a autora demonstra o modelo hierárquico, autoritário e patriarcal de gestão escolar adotado na Argentina até meados do século XX, o que não é diferente em outros países, inclusive no Brasil. Em seu percurso investigativo, descreve as consequiências da pressão democratizadora decorrente dos movimentos civis sobre o acesso aos cargos diretivos, as conquistas desses movimentos com relação à profissionalização do trabalho docente e a democratização dos cargos para as professoras. Nas conclusões, dá realce às tensões de gênero marcantes nos cargos diretivos, pois os homens, por tradição, agregam naturalmente autoridade e legitimidade aos cargos que ocupam e que lhes conferem prestígio e reconhecimento econômico e social; as mulheres conquistam ou constroem a legitimidade de seu poder mediante suas práticas.

Os trabalhos que compõem a produção do GT Formação de Professores, analisados até esse momento, em maior ou menor medida, inscrevem-se em um nível macro de políticas e práticas de formação de professores. Aqueles que se voltam para a análise da prática pedagógica no cotidiano da sala de aula mereceram um tópico específico, objeto do próximo item.

\section{Prática pedagógica: modus operandi do professor no cotidiano da sala de aula}

Dez pesquisas abordaram a questão do cotidiano da escola. Estudar a sala de aula, compreender como ocorrem as interações entre professor e estudantes, entender como nesse processo interativo o conhecimento é construído pelo discentes e quais os desafios que essa atividade mediadora coloca ao professor constituiu uma vertente fértil para aperfeiçoar as práticas docentes e interferir na qualidade de ensino. 
Tendências construtivistas e sociointeracionistas ofereceram subsídios para fundamentar grande parte das análises. Analisar a implementação de um projeto construtivista foi o objeto de uma pesquisa de observação participante, feita por Garrido (1993), em duas salas de ensino de física do ensino médio. As interações em sala de aula foram categorizadas segundo o Modelo de Mudança Conceitual, de Posner et al. (1992). Os resultados buscam desvendar a complexidade da situação de ensino e de aprendizagem, a importância e singularidade da atuação dos docentes na condução dos processos de reconstrução do conhecimento pelos alunos e as atitudes e representações de resistência à proposta construtivista dos alunos e professores.

As pesquisas desenvolvidas por Darsie (1995) e Ludke (1995) investigaram práticas avaliativas O primeiro relatou proposta de avaliação construtivista desenvolvida em uma disciplina do curso de pedagogia. A avaliação da aprendizagem foi empreendida pelos próprios alunos. Para explicitar o processo de mudança conceitual, registraram semanalmente, por escrito, as experiências de aprendizagem vividas em sala de aula, comentando-as. A avaliação é concebida como atividade metacognitiva, mediante a qual o aluno toma consciência do próprio processo de aprendizagem. Ao pensar sobre o que aprendeu e como aprendeu, o estudante avalia o ensino e oferece ao professor elementos de diagnóstico para reformular suas práticas, com o objetivo de favorecer a aprendizagem.

No segundo, foram observadas classes em três escolas públicas de ensino fundamental, constatando, mais uma vez, a predominância de procedimentos avaliativos que aferem sobretudo informações. Nas conclusões, a autora aponta a necessidade de aprofundar essa questão nos cursos de formação de professores, tendo em vista a precariedade das práticas de avaliação observadas.

Simões (1992) e Lima (1995) caminharam por uma segunda via de investigação: levantaram as representações e práticas de professores do ensino superior, por meio de questionários e de entrevistas com os sujeitos da pesquisa e seus alunos. Identificam o predomínio de práticas fundadas na concepção de ensino como transmissão. Uma das constatações de Lima (1995) causa séria preocupação aos que se dedicam à formação de professores: a investigação comprovou não haver diferenças significativas entre as práticas de professores com ou sem formação pedagógica.

Outras contradições entre o discurso e as práticas foram detectadas em um estudo etnográfico em classes de história da $5^{\mathrm{a}}$ a $8^{\mathrm{a}}$ séries. A investigação feita por Matela (1994) mostrou que a nova concepção de história presente nos livros didáticos não havia sido apropriada pelos professores. Em suas aulas, eles oferecem aos alunos uma visão de história baseada em seus saberes, advindos de uma prática descontextualizada.

Linhares (1995), em um estudo de natureza ensaística, explorou a dicotomia entre o discurso crítico-emancipatório das universidades e as práticas reprodutivas do ensino fundamental. Concluiu com uma crítica à academia, desqualificando sua produção, que considerou mera transposição e simplificação de modelos teóricos, sem efetivo compromisso com a construção do conhecimento.

As condições de trabalho na escola influem nas práticas dos professores. A essa conclusão chegou um estudo efetivado por Borges (1996), que observou as aulas de dois professores de educação física em duas escolas, cujas dinâmicas eram diferentes. Os resultados sugerem que os processos de preparação profissional e formação pessoal, nos quais os professores vão construindo os seus conhecimentos, são inseparáveis e que a construção do saber é influenciada pelas condições institucionais de trabalho, bem como pelo modo singular pelo qual cada um construiu a sua identidade profissional em interação com as suas experiências de vida.

Uma terceira vertente procurou registrar o processo de aperfeiçoamento profissional de professores insatisfeitos com suas práticas. Ao tentar compreender como alguns professores foram construindo sua prática docente ao longo do tempo, os pesquisadores desvendaram a profissão docente como processo de autoformação continuada, conduzida de forma individual ou coletiva. Essa nova concepção mostra as limitações da formação 
inicial, fase importante que, no entanto, precisa ter continuidade, ao longo do exercício profissional.

Dois trabalhos relatam esses processos de autoaperfeiçoamento docente em seus locais de trabalho: o de Hoffman e Carneiro (1997) e o de Dickel (1997). $\mathrm{O}$ primeiro investiga o processo de mudança das representações e das práticas docentes de uma professora de ensino superior, insatisfeita com os altos índices de evasão e repetência em sua disciplina. A reflexão sobre sua prática avaliativa foi favorecida pelo diálogo com uma colega da instituição que praticava formas de avaliação construtivistas. $\mathrm{O}$ segundo relata a trajetória de um grupo de professoras das séries iniciais, ao longo de cinco anos, e a possibilidade de realizar sua autoformação. Registros das reuniões de estudo, ao longo de todo esse tempo, revelam as transformações ocorridas. Considerar que o professor pode transformar sua ação em investigação e, desse modo, melhorar sua prática, significa considerá-lo autor de sua prática. E mais do que isso, segundo Stenhouse (1986), Elliott (1990) e Thiollent (1994), significa considerá-lo produtor de conhecimento prático sobre ensino e parceiro necessário do pesquisador.

O movimento de autoformação de professores mostra a reafirmação da identidade profissional, contra a expropriação do trabalho docente.

\section{Revisão de literatura}

Quatro trabalhos apresentam análises da produção do conhecimento sobre formação de professores. Desenvolvidos por Brzezinski e Garrido (1997), Brzezinski (1998), André (1998) e Foerste (1998), propuseram-se a analisar a produção de outros investigadores à luz de suas descobertas.

Essa metodologia de análise da produção do conhecimento é denominada por Ausebel, citado por Moreira (1985), como "reconciliação integrativa" (p. 9). Entendemos que proceder a reconciliação integrativa significa oferecer uma visão compreensiva sobre os avanços na área, os referenciais teóricos usados, delineando tendências de pesquisa, explorando relações, explicitando divergências.
A diversidade de produção do GT Formação de Professores, a riqueza e variedade dos aportes teóricos e a complexidade dos novos desenhos de pesquisa exigiram o debruçar do grupo sobre a história de sua produção, sobre os marcos dessa trajetória, seus avanços, desafios e dilemas. Esses foram os objetivos dos trabalhos apresentados por Brzezinski e Garrido (1997) e Brzezinski (1998).

No primeiro, baseadas em análise documental e história oral, as autoras recuperaram a memória do GT, desde sua criação em 1983 até 1997, e organizaram a produção científica em períodos, assim configurados:

a) primeiro momento - 1983/1985: o GT constituiu-se em um fórum de reflexão sobre os problemas dos cursos de licenciatura, a partir do qual se delineou um programa de estudos, tendo em vista o conhecimento da realidade desses cursos no país;

b) segundo momento - 1986/1991: período marcado pela tentativa de traçar novos rumos para as licenciaturas, a partir de levantamentos sobre os cursos de graduação que formavam professores no país e do exame de práticas inovadoras, centradas em projetos de pesquisa, que começavam a despontar;

c) terceiro momento - 1992/1993: constituído de estudos sobre a articulação da pesquisa com a docência, articulação essa que requeria desenvolver a pesquisa para construir saberes docentes que incluem a prática dos professores, prática que se transforma em objeto de investigação e de reflexão teórica. Pesquisas centradas na interdisciplinaridade também marcaram a produção do GT neste momento;

d) quarto momento - 1994/1997: amplia-se consideravelmente o espectro temático do GT: há pesquisas que focalizam a profissionalização docente, como busca de identidade e reconhecimento da profissão de professor; a formação continuada é bastante investigada e passa a ser entendida como complementar à formação inicial e como processo de desenvolvimento global do professor, integrando as dimensões do ser, do saber e do saber fazer.

As mudanças de perspectiva teórica e de enfoque das pesquisas foram tão profundas, enquanto concepção de formação e do trabalho docente, que implica- 
ram a mudança da denominação do GT: de licenciaturas para Formação de Professores.

No segundo trabalho, Brzezinski (1998) retomou a produção do último período do GT e analisou 40 trabalhos apresentados por 51 pesquisadores de 26 instituições. Nesta pesquisa, foram identificados os núcleos de pesquisa, as áreas temáticas e as linhas de investigação mais explorados pelo GT, assim como os núcleos temáticos e áreas menos exploradas. Embora ainda emergentes, foram considerados importantes para os avanços dos estudos nos GT.

O terceiro trabalho, apresentado por André (1998), revelou os primeiros resultados relativos à formação de professores encontrados em 203 dissertações de mestrado e 33 teses de doutorado, defendidas nos programas de pós-graduação das universidades brasileiras, no período entre 1985-1995.

O quarto, feito por Foerste (1998), selecionou a produção acadêmica sobre as relações entre a universidade e a escola pública, a partir de uma amostra de periódicos nacionais publicados a partir da década de 1980. O autor buscou, em especial, descobrir nos discursos contidos nos artigos o papel da academia na sua relação com a escola básica, em seus diferentes níveis de ensino.

\section{Reafirmando descobertas, apontando alguns caminhos}

A análise dos trabalhos apresentados no GT Formação de Professores, no período entre 1992-1998 mostrou a riqueza e a diversidade de enfoques das investigações, de fundamentos teóricos utilizados, das metodologias de pesquisa e das contribuições sobre a temática. $\mathrm{O}$ conjunto dos trabalhos lançou luz sobre o conhecimento do professor, também produzido na prática, pois não podemos desconhecer, como afirma Gimeno Sacristán (1991), que a prática pedagógica é uma atividade que gera cultura, à medida que é praticada; a prática docente em movimento é produtora de conhecimento, ela é práxis.

As experiências de parceria da universidade com o sistema de educação básica abriram caminhos novos de pesquisa, de revisão de concepções sobre processos de formação e de profissionalização docente.

A participação dos professores, enquanto sujeitos dos processos formativos, apareceu em várias pesquisas de formação inicial e continuada, mas, a voz do aluno praticamente não foi ouvida pelos investigadores. Aliás, os professores foram estudados pelos formadores-pesquisadores. Não foi analisado o formador do professor. Tampouco foram levantados dados sobre como outros profissionais vêem os professores ou como os alunos vêem os docentes. Também nada se estudou a respeito do que os alunos esperam da escola.

A avaliação do impacto dos cursos de formação inicial e continuada na melhoria da qualidade do ensino também foi questão pouco investigada na produção do GT, assim como silenciam-se as pesquisas sobre as condições de trabalho dos professores da rede pública e a influência desse fator nos baixos índices de qualidade e de aproveitamento no ensino fundamental.

No conjunto dos trabalhos, é marcante a recorrência à temática da profissionalização docente, inclusive com o aporte de modelos teóricos expressivos para a construção da identidade profissional do professor. Calam-se porém as pesquisas em relação a um aspecto da profissionalização: o direito à sindicalização e à participação nas associações da categoria e nos movimentos em defesa da valorização do professor. Do mesmo modo, emudecem-se as fontes em relação à carreira docente e aos movimentos de valorização profissional. Políticas públicas de formação docente, de desenvolvimento profissional e de valorização da profissão também são questões que carecem de investigações documentais e de ensaios críticos.

Outro tema recorrente nas pesquisas analisadas é a feminilização do magistério do ensino fundamental. No entanto, merece ainda ser discutida a competência feminina para assumir a gestão de instituições superiores e universidades, como valorização da profissão e como reconhecimento do estatuto social e econômico da mulher como professora.

Apesar dos contínuos aportes visando à melhoria dos cursos de formação inicial de professores, esses cursos têm sido continuamente questionados. Diante 
disso, indagamos: até que ponto os cursos de formação de professores estariam respondendo às necessidades da sociedade pós-industrial, da revolução tecnológica, marcada pela produção científica, pelo desenvolvimento dos meios de comunicação e informação, por desigualdades e tensões sociais alarmantes e por novas formas de exercício da cidadania? Quais os novos papéis do professor? Que formação dar ao educador para que ele possa ser um efetivo agente social transformador inserido nos contextos culturais contemporâneos?

IRIA BRZEZINSKI, doutora em educação pela Universidade de São Paulo, é professora titular da Universidade Católica de Goiás e pesquisadora associada da Universidade de Brasília. Últimas publicações: Fundamentos sociológicos, funções sociais e políticas da escola reflexiva e emancipadora: algumas aproximações. (em Isabel Alarcão, 2001). Escola reflexiva e nova racionalidade. (Porto Alegre: Artmed, p. 65-82); Pedagogia, pedagogos e formação de professores; busca e movimento ( $3^{\mathrm{a}}$ ed. Campinas: Papirus, 2001); em colaboração com José Tavares, Construção do conhecimento profissional; um novo paradigma científico e de formação (Aveiro: Universidade de Aveiro, 1999); Conhecimento profissional de professores; a práxis educacional como novo paradigma (Brasília: Editora Plano \& Fortaleza: Fundação Demócrito Rocha, 2001). Pesquisas em andamento: "Avaliação do Programa de Formação de Professores da UCG: interdisciplinaridade e profissionalização docente"; "Tomar café para falar com professores e alunos sobre pedagogia universitária e sucesso acadêmico", projeto integrado Mestrado em Educação da UCG e Universidade de Aveiro/ Departamento de Ciências de Educação. E-mail: iriaucg@yahoo.com.br

ELSA GARRIDO é professora associada da Faculdade de Educação da Universidade de São Paulo, atuando na área de Didática. Foi coordenadora do GT de Formação de Professores da ANPEd no biênio 1998-1999. Tese de livre-docência, defendida em 2001 na USP: Pesquisa colaborativa universidade-escola e desenvolvimento profissional docente. Últimas publicações: Reflexão sobre a prática e qualificação da formação inicial docente, Cadernos de Pesquisa (nº 107, p. 149-168, jul. 1999); Sala de aula: espaço de construção do conhecimento para o aluno e de pesquisa e desenvolvimento profissional para o professor (em A. D. Castro e A. M. P. Carvalho. Ensinar a ensinar. São Paulo: Pionei- ra, 2000). Pesquisas atuais: "Formação inicial do professor reflexivo/investigativo” e “Formação continuada”.E-mail: egarrido@usp.br

\section{Referências Bibliográficas}

AGUIAR, M. C. A de, MAIA, L. L. P., ROSA, E., (1993). A representação do professor sobre o ensino da Matemática e sua prática pedagógica no decorrer de um processo de formação continuada. Recife: UFPE (mimeo).

ALARCÃO, I., (1998a). Formação continuada como instrumento de profissionalização docente. VEIGA, I. P. A. Caminhos da profissionalização do magistério. Campinas: Papirus, p. 99-122. , (1998b). Profissionalização docente. Anais do II Congresso Internacional sobre formação de Professores nos Países de Língua e Expressão Portuguesas. Porto Alegre: ULBRA., p. 135-141.

ALIN, C., (1996). Être formateur: quand dire c'est ecouter. Paris: L'Harmattan.

ANDALÓ, C. S. de A., (1995). Aperfeiçoamento docente - uma das soluções para o fracasso da escola pública? Florianópolis: UFSC (mimeo).

ANDRÉ, M. E. D. A. de, (1998). Formação de professores nas teses e dissertações brasileiras. São Paulo: USP (mimeo)

ANGOTTI, J. A. P., (1994). Metodologia e prática de ensino: contribuição para transformação das licenciaturas. Florianópolis: UFSC (mimeo).

APPLE, M., TEITELBAUN, K., (1991). Está o professorado perdendo o controle de suas qualificações e do currículo? Teoria e Educação, Porto Alegre: Pannonica, nº 4, p. 62-90.

ASSUNÇÃO, M. M. de S. de., (1995). As determinações de gênero na escolha, formação e prática docente das professoras primárias. Belo Horizonte: UFMG (mimeo).

BASSO, I. S., (1992). O perfil do aluno da licenciatura e a universidade pública. Marília: UNESP (mimeo).

BIRGIN, A., (1998). Nuevas regulaciones del trabajo docente. Buenos Aires: FLACSO (mimeo).

BORGES, C. M. F., (1996). Formação e prática pedagógica do professor de Educação Física: a construção do saber docente. Pelotas: UFPEL (mimeo). 
BRAULT, M., (1994). Profissionalização. In: BRAULT, M. A formação do professor para a educação básica, Perspectivas, Brasília: MEC/Unesco, p. 41-48.

BRZEZINSKI, I., (1992). Avaliação da licenciatura em Pedagogia: relato de um processo. Goiânia: UCG (mimeo).

(1993). Formação de professores: formulação de uma concepção básica na trajetória do movimento das reformulações curriculares. Brasília: UnB (mimeo).

, (1995). O GT Formação de Professores: trajetória de sua consolidação. Belo Horizonte: ANPEd, p. 49-52.

, (1997) Perplexidades na formação de profissionais da educação frente a $L D B$ n. 9394/96: a (re) significação da formação do pedagogo. Brasília: UnB (mimeo).

, (1998). A produção do GT Formação de Professores. Brasília: UnB (mimeo).

BRZEZINSKI, I. e GARRIDO. E., (1997). Pesquisa no GT Formação de Professores: treze anos de produção do conhecimento. Goiânia: UCG/USP (mimeo).

BUENO, B. O., SOUSA, C. P. de, CATANI, D., SOUZA, M. C. de, (1994). Docência, memória e gênero: práticas alternativas de formação de professores. São Paulo: USP (mimeo).

BUENO, B. O., (1997). O método autobiográfico e os estudos com história de vida de professores: a subjetividade e a questão das representações. São Paulo: USP (mimeo).

CARRER, A., BRUNSTEIN, R., BRUNSIZIAN, I., MAKRAY, R. M. A., (1996). Formação continuada e mudanças na prática pedagógica: a eficácia da oficina. São Paulo, CENPEC (mimeo).

CARRER, A.C., BRUNSTEIN, R., CHIEFFI, M. V., (1995). Formação continuada de profissionais do ensino: análise de programas selecionados nas cinco regiões do Brasil. São Paulo: CENPEC (mimeo).

CARROLO, C., (1997). Formação e identidade profissional dos professores. In: ESTRELA, M. T. Viver e construir a profissão docente. Porto: Porto Editora, p. 21-50.

CARVAlHO, A M. P. de., (1992.). Pesquisa em sala de aula: um importante fator na formação do professor. São Paulo: USP (mimeo).

CARVALHO, J. M., SIMÕES, R. H. S., (1996). Formação continuada do professor por meio da pesquisa da sua própria prática. Vitória: UFES (mimeo).
CAStanho, E. C., LOUREIRO, T. C., COSTA, E. A P. C., PUCETTI, R., (1992). Pesquisa psicológica e formação de professores. Campinas: PUCCAMP (mimeo).

CHAKUR, C. R. de S. L., (1994). Profissionalização docente: uma leitura piagetiana de sua construção. Araraquara: UNESP (mimeo).

COLINVAUX, D., (1993). Ciência, escola e vida cotidiana: os contextos do conhecimento em discussão. Rio de Janeiro: UFF (mimeo).

DAMIS, O. T., (1996). O curso de pedagogia da Universidade Federal de Uberlândia: do projeto à concepção dos professores. Uberlândia: UFU (mimeo).

DARSIE, M. M., (1995). Avaliação da aprendizagem e formação do professor. Cuiabá: UFMT.

DELEUZE, G., (1987). Proust e os signos. Rio de Janeiro: Forense.

DICKEL, A., (1997). Aliando pesquisa, práxis e produção coleti$v a$ : a trajetória de um grupo de professoras pesquisadoras na luta pela reapropriação do trabalho docente. Passo Fundo: UPF (mimeo).

, (1998). Buscando referências para a discussão sobre a formação do professor-pesquisador: contribuições para o debate. Passo Fundo: UPF (mimeo).

ELLIOTT, J., (1990). La investigación-acción en educación. Madrid: Morata.

ENGUITA, M. F., (1991). Ambigüidade da docência: entre o profissionalismo e a proletarização. Teoria e Educação. Porto Alegre, Pannonica, nº 4, 1991, p. 41-61.

FELDFEBER, M., (1995). Las políticas de formación docente en Argentina: una mirada a las propuestas de los organismos internacionales. Buenos Aires: UBE (mimeo).

FOERSTE, E., (1997). Universidade e formação de professores: um estudo sobre o Fórum de licenciatura da UFG. Goiânia: UFG (mimeo).

, (1998). Discurso de alguns periódicos nacionais sobre formação de professores e a integração universidade $e$ escola a partir dos anos 80. Vitória: UFES (mimeo).

FOUCAULT, M., (1991).Tecnologías del yo. Barcelona: Paidós. , (1993). Microfísica do poder. Rio de Janeiro: Graal. , (1994). Dits et écrits. Paris: Gallimard. 
FREITAS, H. C. L. de., (1993). Trabalho e relação teoria-prática nos estágios supervisionados de $1^{\circ}$ grau do curso de pedagogia. Campinas: UNICAMP (mimeo).

GARCIA, C. M., (1992). A formação de professores: novas perspectivas baseadas na investigação sobre o pensamento do professor. In: Novoa, A. Os professores e sua formação. Lisboa: Don Quixote, p. 51-76.

GARRIDO, E., (1993). Ensino construtivista de ciências: análise da interação verbal professor-aluno. São Paulo: USP (mimeo). , (1998). Metodologia da pesquisa-ação e formação de professores reflexivos: redefinindo o universo epistemológico e discutindo as implicações prático-metodológicas. São Paulo, USP (mimeo).

GIMENO SACRISTÁN, J., (1991). Consciência e acção sobre a prática como libertação profissional dos professores. In: NÓVOA, A., (org.). Profissão professor. Cidade do Porto: Porto Editora, p. 61- 92.

, (1996). Compreender y transformar la enseñanza.

Madrid: Morata.

GIROUX, H. A., (1997). Os professores como intelectuais: rumo a uma pedagogia crítica da aprendizagem. Porto Alegre: Artes Médicas.

GONÇALES, M. H., (1995). Atitudes (des)favoráveis com relação à Matemática. Campinas: UNICAMP (mimeo).

GRILLO, M., AZMBUJA et al., (1998).Transposição didática: uma prática reflexiva. Porto Alegre: PUCRS (mimeo).

GUATTARI, Félix, (1992). Caosmose, um novo paradigma estético. Rio de Janeiro: Editora 34.

HOFFMANN, J. M. L., CARNEIRO, V. C., (1993). O ensino de Matemática versus avaliação numa perspectiva construtivista: um diálogo possível? Porto Alegre: UFRGS (mimeo)

KINCHELOE, J. L., (1997). A formação do professor como compromisso político. Porto Alegre: Artes Médicas.

LEVY, M. I. C. de, PUIG, N. S., (1998). Melhoria do processo ensino-aprendizagem da ciência a partir da reflexão dialógica entre professor e orientador, das concepções e práticas. Barcelona: FURG/UAB (mimeo).

LIMA, E. F. de, (1995). Professores de $3^{\circ}$ grau com e sem formação pedagógica: relato de suas concepções e vivências. São Carlos: UFSCAR (mimeo).
, (1997). O pensamento do professor: construindo metáforas, projetando concepções. São Carlos: UFSCAR (mimeo).

LINHARES, C. F. S., (1995). Formação de professores no Brasil: entre o discurso acadêmico-pedagógico e a escola pública fundamental. Rio de Janeiro: UFF (mimeo).

LUDKE, M., (1995). Avaliação e formação de professores. Rio de Janeiro, PUC-Rio (mimeo).

LUDKE, M., GOULART, S., (1994). licenciatura; novos caminhos pela via da interdisciplinaridade. Rio de Janeiro: PUC/RJ (mimeo).

MARIN, A., (1998). Metodologia pesquisa-ação e formação de professores reflexivos: redefinindo o universo epistemológico e discutindo as implicações prático-metodológicas. São Paulo: UNESP/USP (mimeo).

MARTINS, A. de F., (1998). O desenho reproduzido e a formação do professor das séries iniciais do ensino fundamental. Brasília: UnB (mimeo).

MARTINS, R. B., (1994). De uma experiência de "treinamento" a algumas lições e desafios. Ponta Grossa: UEPG (mimeo).

MATELA, R. C. P., (1994). O professor de História e o livro didático: uma relação delicada. Rio de Janeiro: UFF (mimeo).

MAZZOTTI, M. A., (1993). A possibilidade de uma educação científica. Cuiabá: UFMT (mimeo).

MELO, M. M. de O., (1995). A formação do profissional do magistério e a nova lógica de organização das licenciaturas. Recife: UFPE (mimeo).

MORAES, A. A. de A., (1996). História de vida: a trajetória pessoal/profissional de uma professora de leitura. São Carlos, UFAM/UFSCAR, (mimeo).

MOREIRA, M. A., (1995). Ensino e aprendizagem: o significado de alguns conceitos básicos segundo diferentes perspectivas teóricas. In: MOREIRA, M. A. (org.). Ensino na universidade. Porto Alegre: UFRGS, 1985.

MORGADE, G. Al., (1998). Dinámicas de género en los discursos constitutivos de la gestión de las escuelas argentinas. Buenos Aires: UBA (mimeo).

NÓVOA, A., (1991). O passado e o presente dos professores. In: NÓVOA, A. (org.). Profissão professor. Porto: Porto Editora, p. 9-32. 
,(1992a) Os professores e sua formação. Lisboa: Dom Quixote.

, (1992b). As organizações escolares em análise. Lisboa: Don Quixote.

NUÑEZ, I. B., RAMALHO, B. L., (1997). Um modelo profissional: uma necessidade para a formação do professor. Natal: UFRN (mimeo).

PAIVA, A., FREITAS, H. de, SCHEIBE, L., (1997). Pedagogia: políticas de formação de professores e mudanças curriculares. Brasília: UFMG/UNICAMP/UFSC (mimeo).

PEREIRA, J. E. D., (1997). Representações sobre ensino na universidade e suas implicações para as licenciaturas. Belo Horizonte: UFMG (mimeo).

PEREIRA, M. V., (1996). Sobre o trabalho interdisciplinar como estratégia de produção de subjetividade na formação de professores. Pelotas: UPEL (mimeo).

(1997). Estética da professoralidade. Pelotas: UPEL (mimeo).

PERRENOUD, P., (1993). Práticas pedagógicas, profissão docente e formação. Lisboa: Dom Quixote.

POLETTINI, A. de F. F., (1997). Pressão influenciando mudança e desenvolvimento do professor: o caso de Sara. São Paulo: UNESP (mimeo).

POSNER, G.J. et al., (1992). Acommodation of scientific conception: toward a theory of conceptual change. Science Education, v. 2, n. 66, p. 221-227.

PRETTE, Z. A. P. D., PRETTE, A. D., (1997). Um programa de desenvolvimento de habilidades sociais na formação continuada do professor. Florianópolis: UFSC (mimeo).

RODRIGUES, M. de L., (1997). Sociologia das profissões. Lisboa: Editora Celta, p. 7-45.

ROSSO, A. J., ETGES, N. J., (1996). O que pensam os professores de Ciências e Matemática sobre Educação? Jataí: UNIVALI (mimeo).

SCHÖN, D., (1987). Educating the reflective practitioner. S. Francisco: Jossey-Bass Publishers

, (1992). Formar professores como profissionais reflexivos. In: NOVOA, A. Os professores e sua formação. Lisboa: Dom Quixote.
SILVA, L. H. de A., SCHNETZLER, R. P., (1998). Buscando o caminho do meio: construindo a parceria entre professores $e$ formadores de professores de ciências. Piracicaba: UNIMEP (mimeo).

SILVA, V. L. G da., (1994). Alguns aspectos e valores da identidade social e profissional de professores de $1^{a}$ a $4^{a}$ séries. Florianópolis: UDESC (mimeo).

SIMÕES, R H S., (1993). O papel dos fundamentos sociohistóricofilosóficos da educação nos cursos de magistério do $2^{\circ}$ grau. Vitória: UFES.

SIMÕES, S. P., (1992). A postura teórica e a prática do professor de didática no ensino superior. Rio de Janeiro: UERJ (mimeo).

SOBREIRA, H. G., (1996). Formação de professores: dois tópicos de uma elaboração alternativa. Rio de Janeiro: UERJ (mimeo).

, (1998). Imagens de família e prática docente: anotações preliminares. Rio de Janeiro: UERJ (mimeo).

SORDI, M. R. L. de, CAMARGO, A. L. C., (1998). A formação do professor em situação de trabalho e o papel da universidade: competência aliada à produção. Campinas: PUCCAMP/ $\mathrm{UNICAMP}$ (mimeo).

SOUZA, J. V. de., (1994). A função social do professor subjacente às concepções educacionais reproduzidas elou construídas no cotidiano do Curso Normal do DF: a contribuição da Sociologia da Educação. Brasília: UnB (mimeo).

STENHOUSE, L., (1986).La investigación como base de la enseñanza. Madrid: Morata.

TAFFAREL, C. N. Z., (1992). Formação do profissional do ensino de Educação Física. Recife: UFPE (mimeo). , (1994). O processo de trabalho pedagógico e o trato com o conhecimento no Curso de Educação Física. Recife: UFPE (mimeo).

THIOLLENT, M., (1994). Metodologia da pesquisa-ação. São Paulo: Cortez.

VIANA, D. M., (1992). Uma disciplina integradora: instrumentação para o ensino. Rio de Janeiro: UFRJ (mimeo).

VEIGA, I. P. A., (1996). O curso de Pedagogia da FAE/UnB na perspectiva de coordenadores de professores. Brasília: UnB (mimeo). 
VEIGA, I. P. A.; RESENDE, L. M. G. de; SOUZA, L. C. de, (1993).

Formação contínua de profissionais da educação e a extensão universitária. Brasília: UnB (mimeo).

VIGOTSKY, L.S., (1987). Pensamento e linguagem. São Paulo: Martins Fontes. , (1987b) Imaginación y el arte en la infancia. Madri: Hispanicas.

VILLA, F. G., (1996). Sociología del profesorado. Barcelona: Ariel Educación.
, (1997). O professor frente às mudanças culturais $e$ sociais. Salamanca: Universidade de Salamanca (mimeo). , (1998). Crise do professorado; uma análise crítica. Campinas: Papirus.

WILENSKY, H., (1964). The profissionalisation of everyone? American Journal of Sociology, LXIX, p. 142-146.

ZEICHNER, K. M., (1993). A formação reflexiva de professores: idéias e práticas. Lisboa: Educa. 
mais ligados aos movimentos sociais, que recorrem dominantemente à teoria social e à antropologia e os autores mais ligados a questões pedagógicas, que tendem a se apoiar na teorização de currículo, na teoria crítica, nos estudos culturais e no pensamento pósmoderno e pós-estrutural.

\section{Recent scientific production on} curriculum and multiculturalism in Brazil (1995-2000): advances, challenges and tensions

This article presents an analysis of recent Brazilian scientific production on curriculum and multiculturalism. It examines articles published between 1995 and 2000 in the following journals: Cadernos de Pesquisa, Revista Brasileira de Educação, Educação \& Realidade, Educação \& Sociedade e Educação em Revista. It also focuses on papers presented at the Annual Meetings of ANPEd during the same period. The study aims at identifying the main themes and arguments, the most significant theoretical influences, the methodological procedures employed, the contributions and the gaps. The tensions and challenges observed in the articles are also discussed. The paper insists on the importance of a dialogue between those authors more closely associated with social movements who are chiefly influenced by social theory and anthropology and those authors more closely associated with curriculum and pedagogy who are influenced by critical theory, cultural studies, post-modernism and post-structuralism.

Iria Brzezinski e Elsa Garrido

Análise dos trabalhos do GT Formação de Professores: o que revelam as pesquisas do período 1992-1998

O texto analisa setenta trabalhos apresentados no GT Formação de Profes- sores da ANPEd, no período19921998. As pesquisas foram organizadas segundo cinco descritores: formação inicial de professores, formação continuada, práticas pedagógicas, profissionalização docente e revisão da literatura sobre formação de professores. $\mathrm{O}$ estudo procura oferecer uma visão compreensiva sobre as questões, os referenciais teóricos e os avanços do conhecimento na área, explorando relações, explicitando divergências e delineando tendências de pesquisa. $\mathrm{O}$ conjunto dos trabalhos traz contribuições para fundamentar e subsidiar propostas e políticas de formação e de desenvolvimento profissional docente.

\section{Papers presented in the Working Group on Teacher Formation - what the research in the period 1992-1998 reveals}

This texts sets out to analyse seventy papers presented in the ANPEd Working Group on Teacher Formation during the period 1992-1998. The research was organised employing five categories: initial teacher formation, continued formation, pedagogical practices, teacher professionalisation and literature review on teacher formation. The study seeks to offer a comprehensive vision with regard to theoretical frameworks and recent advances in the area, exploring relations, expressing divergences and outlining research tendencies. The set of papers offers contributions to substantiate proposals and policies for teacher formation and professional development.

\section{Maria Rita Neto Sales Oliveira}

Do mito da tecnologia ao paradigma tecnológico; a mediação tecnológica nas práticas didático-pedagógicas O objetivo principal do texto é apresentar uma visão crítica da tecnologia no âmbito da educação e do ensino.
Aborda três hipóteses sobre a matéria: tecnologia educacional revisitada, modelo da competência e mito da tecnologia, evidenciando seus problemas, reducionismos e limites. Em sequiência, discute as características do novo paradigma tecnológico, e alguns aspectos do Livro verde do Ministério da Ciência e Tecnologia do país. Como conclusão, levanta algumas implicações da necessária superação dos problemas apontados, para o entendimento e tratamento crítico das tecnologias nas práticas didático-pedagógicas.

From the myth of technology to the technological paradigm: technological mediation in pedagogical practices The main objective of the text is to present a critical perspective on technology in education and teaching. Three hypotheses are discussed: educational technology revisited, the competence model and the myth of technology. The text also discusses the characteristics of the new technological paradigm and some aspects of The green book published by the brazilian Ministry of Science and Technology. In conclusion, the article points to some of the implications linked to a critical understanding and treatment of technology in teaching and educational practice.

Bernardete Angelina Gatti

Reflexão sobre os desafios da pósgraduação: novas perspectivas sociais, conhecimento e poder $\mathrm{O}$ artigo salienta as diferenças entre o momento histórico em que os programas de mestrado e doutorado foram criados e o momento atual. Discute-se o papel social desses cursos na dicotomia conhecimento $x$ poder e o dilema a ser enfrentado por mestrados e doutorados que vêm sendo instados, pela sociedade, a abrir-se a novas modali- 